\title{
Noise Reduction in Spur Gear Systems
}

\author{
Aurelio Liguori $^{1}\left(\mathbb{D}\right.$, Enrico Armentani ${ }^{2}\left(\mathbb{D}\right.$, Alcide Bertocco ${ }^{2}$, Andrea Formato ${ }^{3, *}(\mathbb{D}$, \\ Arcangelo Pellegrino ${ }^{4}$ and Francesco Villecco ${ }^{4}$ (i)
}

1 Degree Course in Transport, University “G. Fortunato”, Viale Raffaele Delcogliano, 12, 82100 Benevento, Italy; A.Liguori@Unifortunato.Eu

2 Department of Chemical, Materials and Production Engineering, University of Naples "Federico II", Piazzale V. Tecchio, 80, 80125 Napoli (NA), Italy; enrico.armentani@unina.it (E.A.); alcide.bertocco@unina.it (A.B.)

3 Department of Agricultural Science, University of Naples "Federico II", Via Università 100, 80045 Portici (NA), Italy

4 Department of Industrial Engineering, University of Salerno, Via Giovanni Paolo II, 132, 84084 Fisciano, Italy; apellegrino@unisa.it (A.P.); fvillecco@unisa.it (F.V.)

* Correspondence: formato@unina.it; Tel.: +39-081-253-9150

Received: 1 October 2020; Accepted: 6 November 2020; Published: 16 November 2020

check for updates

\begin{abstract}
This article lists some tips for reducing gear case noise. With this aim, a static analysis was carried out in order to describe how stresses resulting from meshing gears affect the acoustic emissions. Different parameters were taken into account, such as the friction, material, and lubrication, in order to validate ideas from the literature and to make several comparisons. Furthermore, a coupled Eulerian-Lagrangian (CEL) analysis was performed, which was an innovative way of evaluating the sound pressure level of the aforementioned gears. Different parameters were considered again, such as the friction, lubrication, material, and rotational speed, in order to make different research comparisons. The analytical results agreed with those in the literature, both for the static analysis and CEL analysis-for example, it was shown that changing the material from steel to ductile iron improved the gear noise, while increasing the rotational speed or the friction increased the acoustic emissions. Regarding the CEL analysis, air was considered a perfect gas, but its viscosity or another state equation could have also been taken into account. Therefore, the above allowed us to state that research into these scientific fields will bring about reliable results.
\end{abstract}

Keywords: noise reduction; gearboxes; entropy; coupled Eulerian-Lagrangian analysis

\section{Introduction}

Under working conditions, spur gears are simultaneously subjected to mechanical and thermal loads, both of which are strictly related to noise emissions. Specifically, the transmitted torque affects the maximum stress on the teeth, rotational speed affects the cyclic loading, and friction leads to increased temperature in the gears and surrounding air. In [1], the interactions between gears and the air is considered, whereby the modeling air is treated as a one-dimensional ideal gas with constant entropy $(\mathrm{ds}=0)$ and an adiabatic flow. The unification of the laws of thermodynamics and Newtonian mechanics has been pursued by many scientists in the last century. The principles are based on using entropy as a bridge between mechanics and thermodynamics [2]. Mechanothermodynamics (MTD) combines two branches of physics-mechanics and thermodynamics-to study the evolution of complex systems. For example, the theory of elasticity assumes that there is no entropy generation at the material level [3]. As a result, everything is reversible, which violates the second law of thermodynamics. The above approaches and models for the energy and stress-strain states of complex systems under thermodynamic and mechanical loads are considered in [4-6]. Damage and entropy 
concepts are important for building a model of an MTD system. Entropy-based models are often used for damage detection in cycling and creep load conditions [7-9]. Additionally, acoustic signals are often used for damage and fault detection [10,11]; therefore, noise and entropy should be related.

When gears work, especially under high loads and speeds, the noise and vibration caused by the rotation of the gears can be unbearable for people [12-14]. Even if it is possible to use some countermeasures against noise on the gears after they have been designed and built, in the design phase of a gearbox, predicting all of the noise reduction factors related to meshing and components-such as the supports, the transmission shafts, and the cases-is always preferred. In fact, transmission shafts, bearings, and their respective cases affect the acoustic emissions in a significant way, and they can be monitored during the design phase [15-17]. Meshing errors resulting from tolerances create an oscillation motion overlaying the uniform rotation of the mechanisms. These oscillations generate dynamic loads on the teeth acting on the transmission shaft, which deflect and consequently create dynamic loads on the bearings, meaning that gear case is excited and produces noise. If the natural vibration frequencies of the shaft and the case are equal to those of the gears, these two components enter into resonance and there is a remarkable amplification of noise [18-22]. Therefore, during the design phase, it is necessary to act on every component involved in the generation of noise. It is possible to achieve reductions in noise in different ways, such as by improving the kinematic precision of the system and by increasing the contact ratio so that dynamic loads on the teeth are reduced.

After minimizing the excitation resulting from the transmission device, it is possible to consider the dynamic loads acting on bearings. These can be reduced by changing the response of the support shaft system. In fact, transmission shafts can be stiffened so that their deflection is reduced and the teeth alignment improves. These changes remarkably reduce the noise of the gear device and improve the durability of bearings and other linked components. The dynamic response of the case can be changed by stiffening its internal or external surface and increasing its thickness [23-25]. It has to be taken into account that the teeth profiles can be changed to avoid interferences resulting from the deflection of shafts, bearings, and cases during meshing and separation phases. If these interferences are not balanced by some changes in the teeth profile, the load capacity of the gears will be decreased. It is possible to make changes to the tip or the flank. Profile changes are very important for high-load and high-speed gears. Other important parameters influencing the design of gears and their noise are the machining tolerances. With good tolerances, it is possible to obtain a remarkable reduction in noise, even for low-quality gears. However, it is necessary to remember that depending on the shape and model of the device, improvement of the teeth surface finish will lead to much higher costs, which can be more than half of the price of the device. Therefore, such expensive changes will not be easily accepted if they are simply for noise reduction purposes [26-28]. As mentioned previously, such toothed devices must have an appropriate backlash so that interferences during the meshing phase are avoided. In fact, tips and flanks that have too much backlash are very noisy because of the interactions between the teeth during no load or load inversion phases. For high-speed transmissions, even a small increase in the backlash can reduce the noise resulting from air and oil ejection-this often occurs in spur gear pairs, which are more likely to have noise problems. An added backlash on the root of a tooth helps to reduce the ejection speed, which can be achieved by increasing the total depth of the tooth. However, the benefits resulting from the reduction in noise must be calculated carefully because of the potential resistance loss for the teeth. However, when these sophisticated techniques are not appropriate from an engineering perspective, it is necessary to focus on the design of the case if we want to improve its dynamic response [29-33]. There are some important rules in this regard, such as avoiding big surfaces and small curvatures, since they vibrate uncontrollably if they are excited. Therefore, curvatures must be used only to stiffen the areas of the case that are characterized by high-energy stress intensity. If stiffening layers cannot be used, these sectors should have greater thicknesses so that they are more rigid than the other areas. However, this method has some restrictions, since a balance must be reached between the weight and project requirements. Therefore, the noise absorbed by the case system has to be evaluated carefully. In this report, through the mean analysis 
performed using the FEM program code, it was possible to describe how stresses resulting from meshing gears affected the acoustic emissions [34-37].

\section{Materials and Methods}

To perform the noise evaluation for the spur gears, FEM modeling and numerical simulation were performed. The first step in the FEM analysis was designing a spur gear pair. This was achieved using SolidWorks. The design parameters are shown in the following table (Table 1).

Table 1. Parameters and corresponding values for the spur gears.

\begin{tabular}{cc}
\hline Parameters & Values \\
\hline Number of teeth N & 55 \\
Module & 2.72 \\
Pitch circle & $150 \mathrm{~mm}$ \\
Dedendum circle & $142.50 \mathrm{~mm}$ \\
Addendum circle & $156 \mathrm{~mm}$ \\
Circular pitch & $6.5^{\circ}$ \\
Pressure angle & $20^{\circ}$ \\
\hline
\end{tabular}

\section{FEM Static Analysis of a Spur Gear Pair}

To perform the FEM static analysis of the spur gear pair, the Abaqus/CAE 6.14-5 program code was used. The considered model was discretized using C3D8 brick elements, giving an 8-node linear brick (Abaqus Manual). The following picture (Figure 1) shows the modeled spur gears.

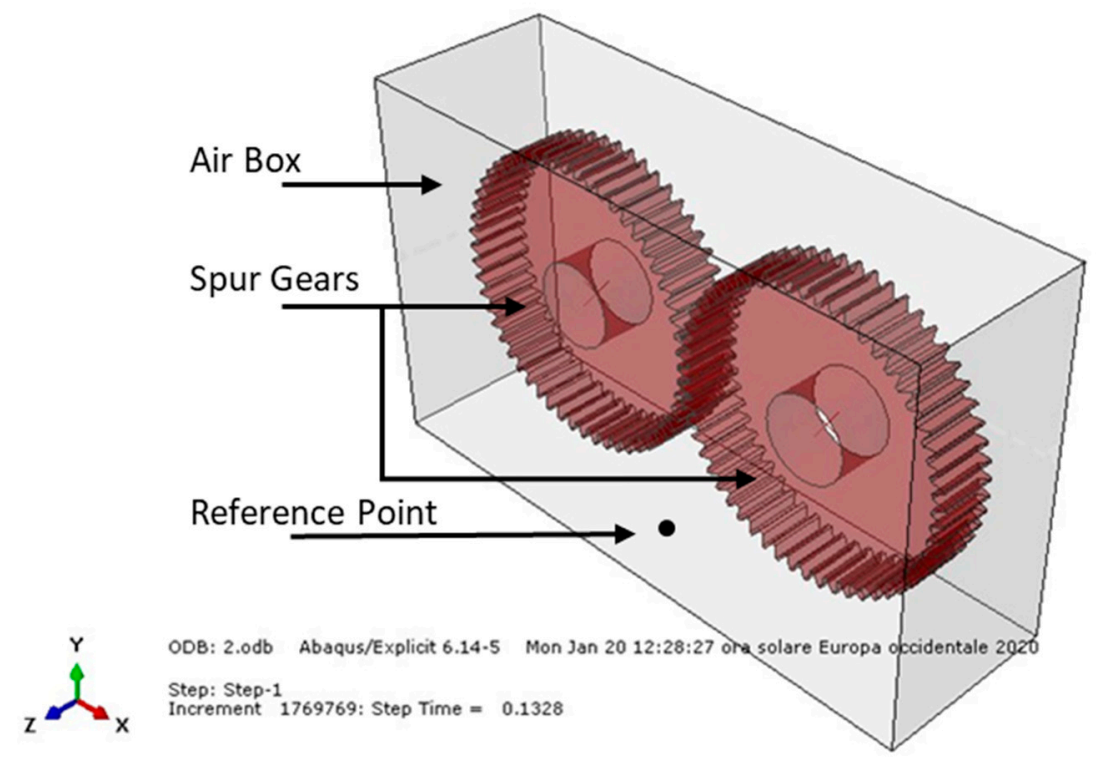

Figure 1. Spur gear assembly model geometry (isometric view).

Regarding the FEM static analysis of the spur gear pair, five conditions were considered in order to evaluate the stress resulting from the meshing of the gears, since their acoustic emissions are influenced by the stresses resulting from the contact point $[38,39]$. Different parameters were taken into account for each condition considered, as shown in Table 2. 
Table 2. Parameters of the conditions considered.

\begin{tabular}{|c|c|c|c|}
\hline Condition & Friction & Material Parameters & Lubricated Friction \\
\hline A & $\mathrm{NO}$ & Steel & $\mathrm{NO}$ \\
\hline B & $\begin{aligned} \mu_{s} & =0.74 \\
\mu_{k} & =0.57 \\
d_{c} & =0.2\end{aligned}$ & Steel & $\mathrm{NO}$ \\
\hline $\mathrm{C}$ & $\mathrm{NO}$ & Ductile Iron & $\mathrm{NO}$ \\
\hline $\mathrm{D}$ & $\begin{array}{c}\mu_{s}=1.1 \\
\mu_{k}=0.15 \\
d_{c}=0.2\end{array}$ & Ductile Iron & $\mathrm{NO}$ \\
\hline E & $\mathrm{NO}$ & Steel & $\begin{array}{c}\mu_{s}=1.1 \\
\mu_{k}=0.15 \\
d_{c}=0.2\end{array}$ \\
\hline
\end{tabular}

An exponential decay friction model $(\mu)$ was adopted (Figure 2 ). It was necessary to insert the static friction coefficient $\mu_{s}$, the kinetic friction coefficient $\mu_{k}$, and the decay coefficient $d_{c}$ as well. This model was based on the following equation, where $\Upsilon$ is the slip rate:

$$
\mu=\mu_{k}+\left(\mu_{s}-\mu_{k}\right) e^{-d_{c} \Upsilon}
$$

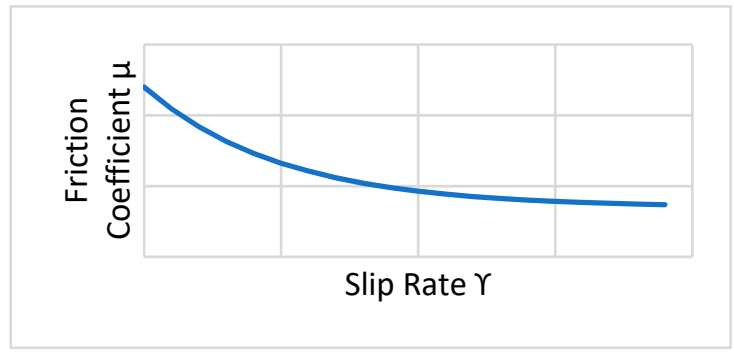

Figure 2. Exponential decay friction model.

\section{Results}

Condition A: The first analysis involved a steel spur gear pair and was characterized by frictionless contact. The results are shown in Figures 3 and 4.

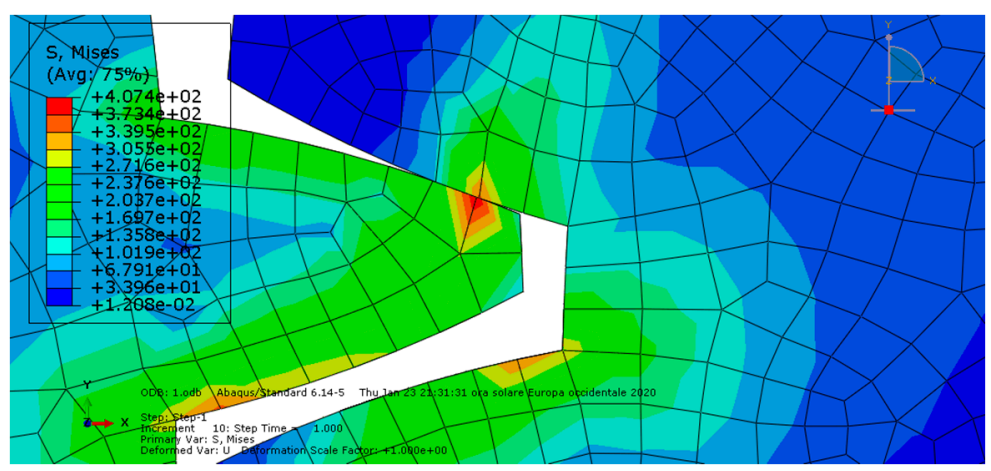

Figure 3. Condition A: The von Mises stress at the contact. 


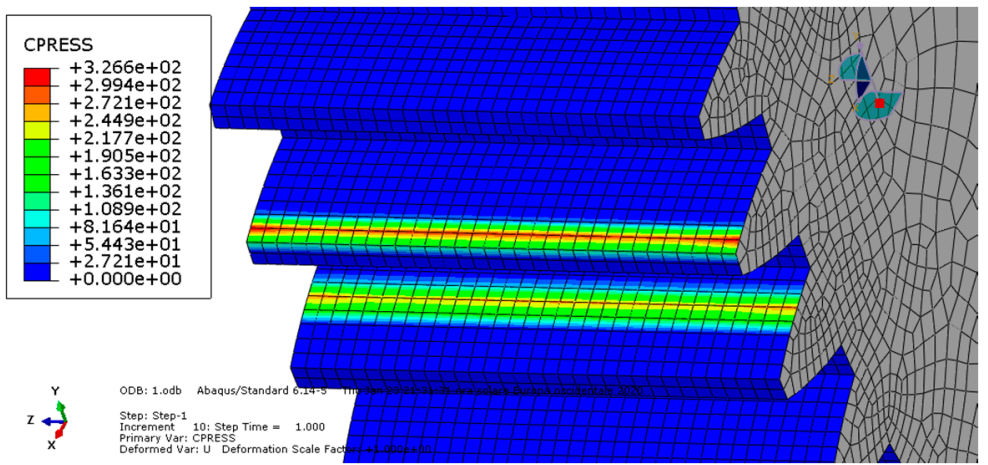

Figure 4. Condition A: Contact pressure along the tooth.

As we can see, the maximum von Mises stress equaled $407 \mathrm{MPa}$, while the contact pressure on the tooth amounted to $327 \mathrm{MPa}$.

Condition B: The second analysis involved a steel spur gear pair and was characterized by the mentioned exponential-decay-based friction model. The results are shown in Figures 5 and 6.

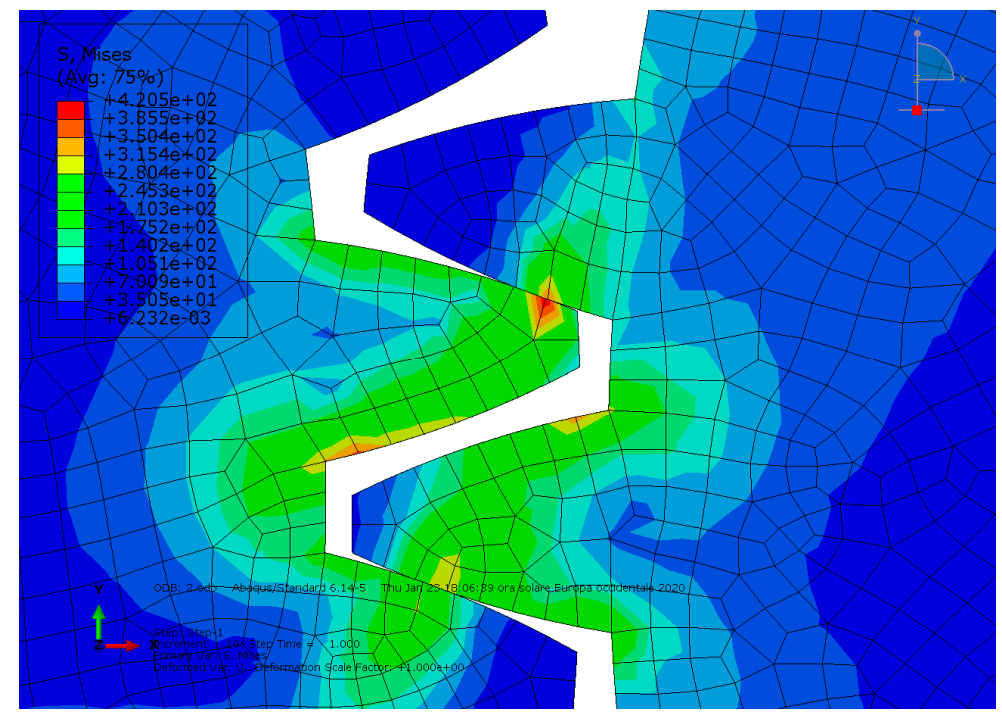

Figure 5. Condition B: The von Mises stress at the contact.

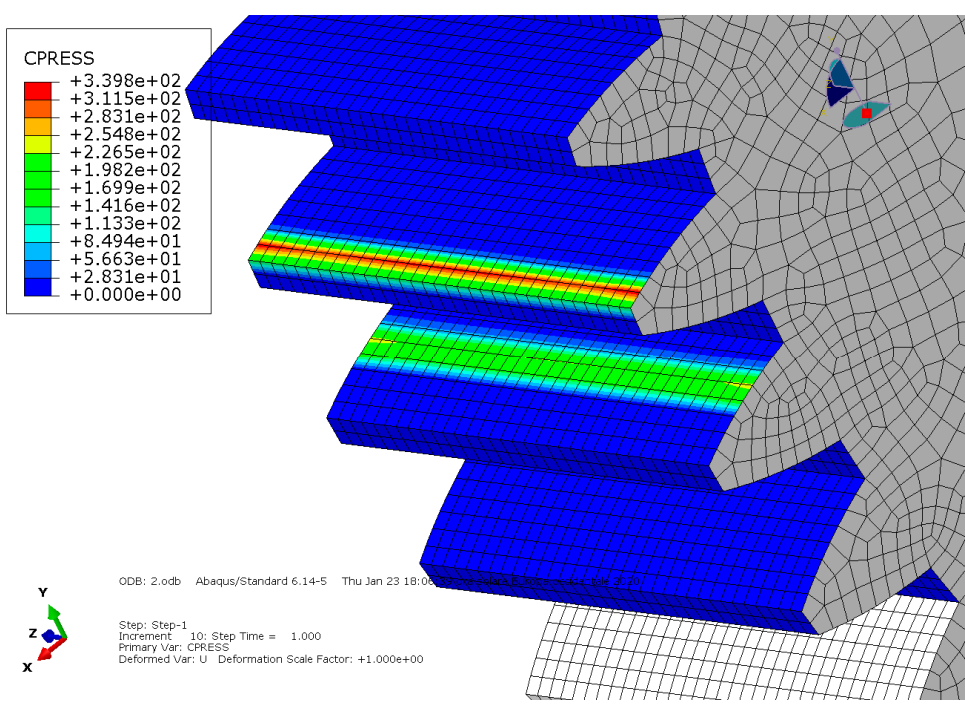

Figure 6. Condition B: Contact pressure along the tooth. 
Condition C: The third analysis involved a ductile iron spur gear pair and was characterized by frictionless contact. The results are shown in Figures 7 and 8.

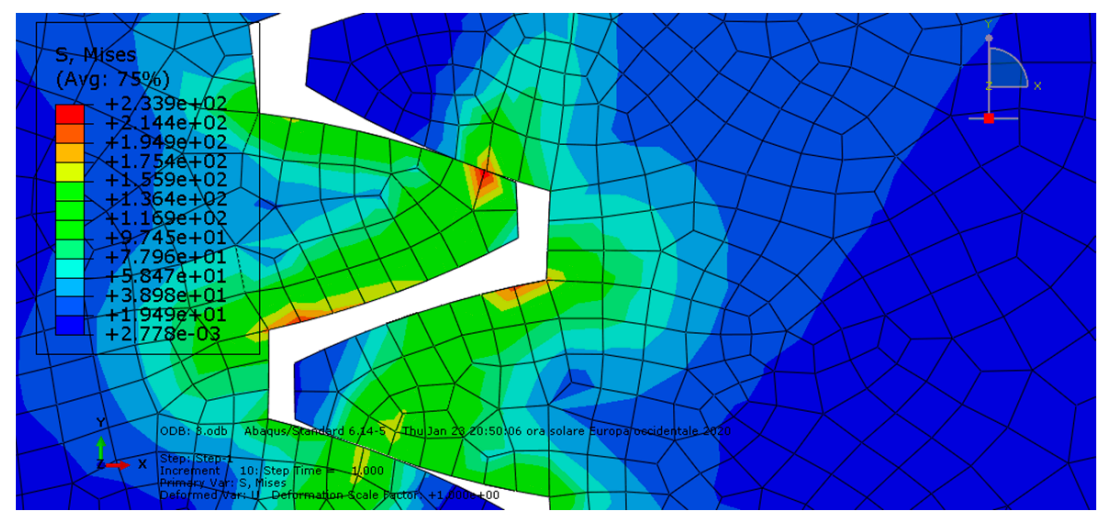

Figure 7. Condition C: The von Mises stress at the contact.

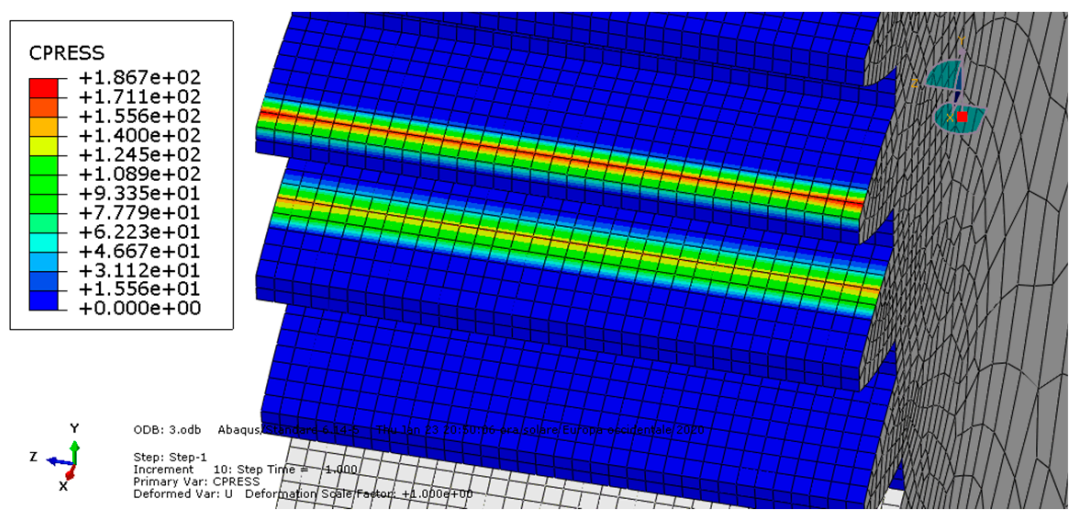

Figure 8. Condition C: Contact pressure along the tooth.

As we can see, the maximum von Mises stress equaled $234 \mathrm{MPa}$, while the contact pressure on the tooth amounted to $187 \mathrm{MPa}$.

Condition D: The fourth analysis involved a ductile iron spur gear pair and was characterized by the mentioned exponential-decay-based friction model. The results are shown in Figures 9 and 10.

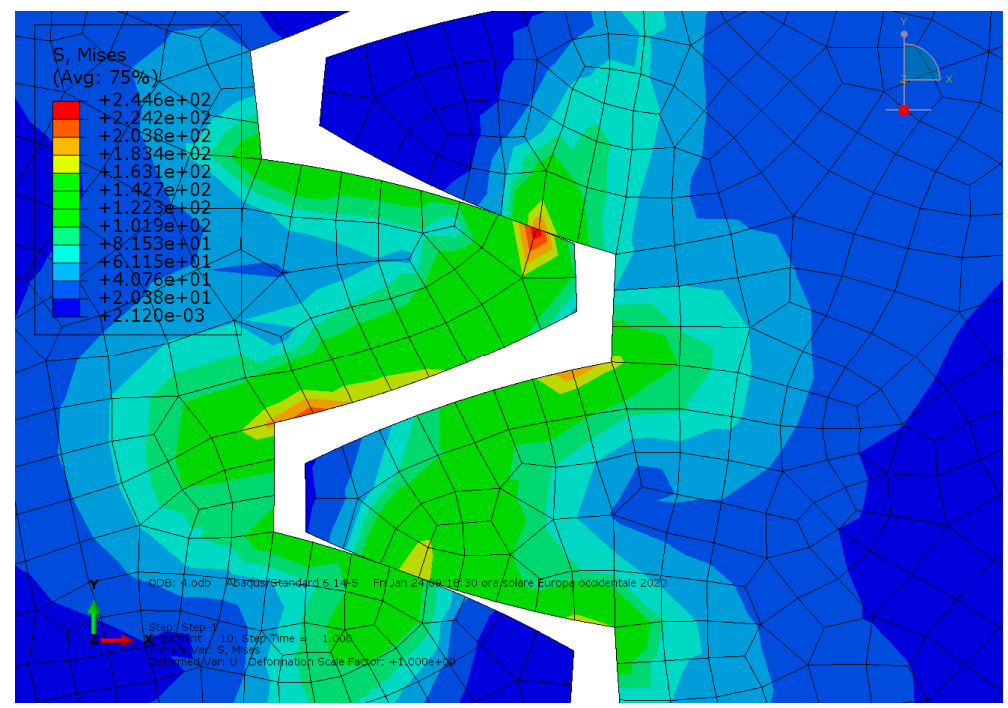

Figure 9. Condition D: The von Mises stress at the contact. 


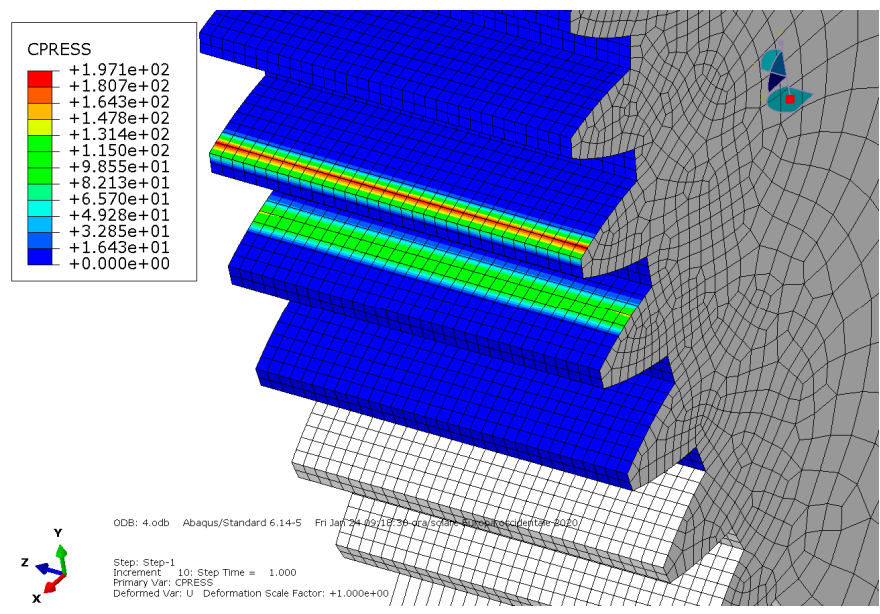

Figure 10. Condition D: Contact pressure along the tooth.

As we can see, the maximum von Mises stress equaled $245 \mathrm{MPa}$, while the contact pressure on the tooth amounted to $197 \mathrm{MPa}$.

Condition E: The fifth analysis involved a steel spur gear pair and was characterized by the mentioned exponential-decay-based lubricated friction model. The results are shown in Figures 11 and 12.

As we can see, the maximum von Mises stress equaled $412 \mathrm{MPa}$, while the contact pressure on the tooth amounted to $332 \mathrm{MPa}$.

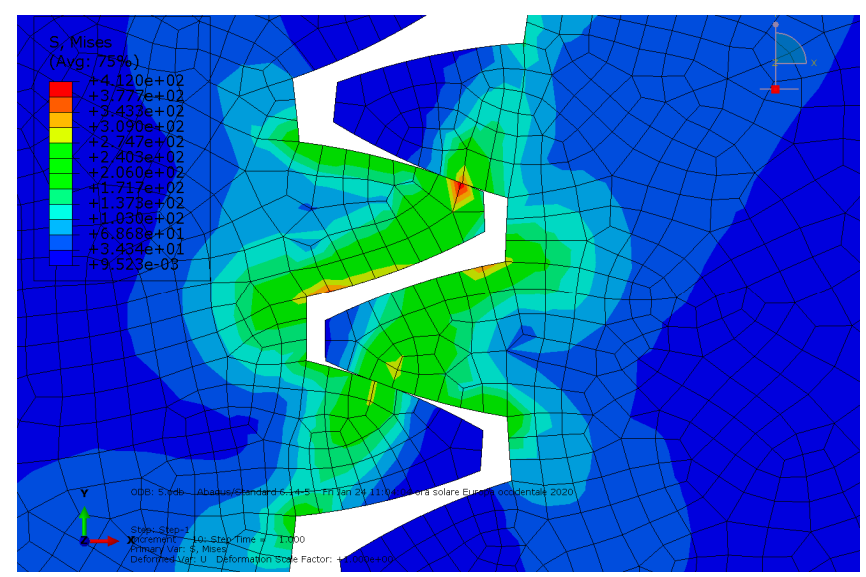

Figure 11. Condition E: The von Mises stress at the contact.

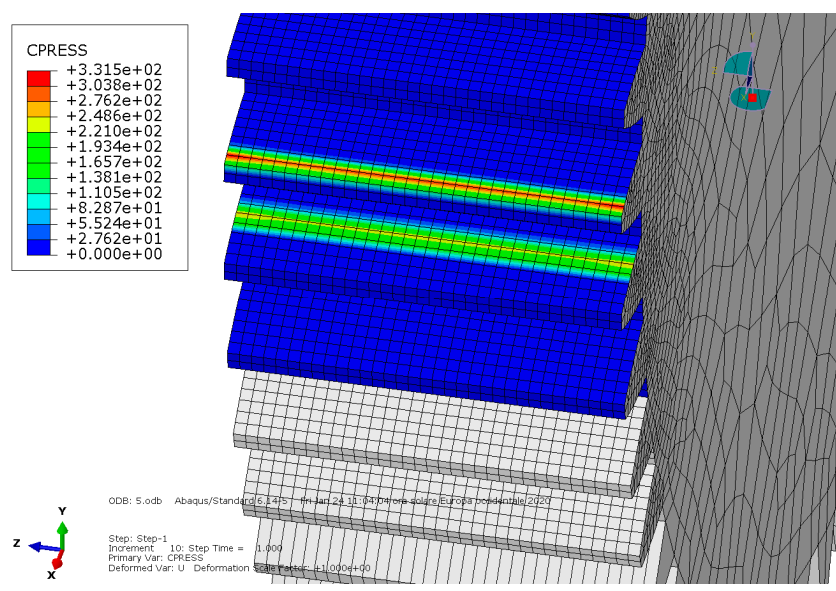

Figure 12. Condition E: Contact pressure along the tooth. 


\subsection{Comparisons}

First Analysis (Condition A) versus Second Analysis (Condition B)

The second analysis (condition B) showed higher von Mises stress and contact pressure values than the first one, so the presence of friction made the stress increase together with the sound excitation, as previously mentioned for this parameter.

Third Analysis (Condition C) versus Fourth Analysis (Condition D)

As we can see in the third and fourth analyses, the ductile iron spur gears had lower von Mises stress and lower contact pressure values, in agreement with comments regarding gear materials and ductile iron properties. Therefore, the sound excitation was lower as well.

Fifth Analysis (Condition E) versus First Analysis (Condition A)

The fifth analysis showed that lubricated friction made the stress decrease together with the contact pressure, leading to agreement that the oil coating reduced the sound excitation of the gears.

First Two Analyses (Conditions A and B) versus Third and Fourth (Conditions C and D) Analyses

The first two analyses (conditions A and B), which involved steel spur gear pairs, showed higher stress values than the third and fourth analyses, which involved ductile iron spur gears. These results again validated the previously mentioned theories about noise in gears.

In Figure 13, the diagram shows the von Mises stress trends between the different analyses.

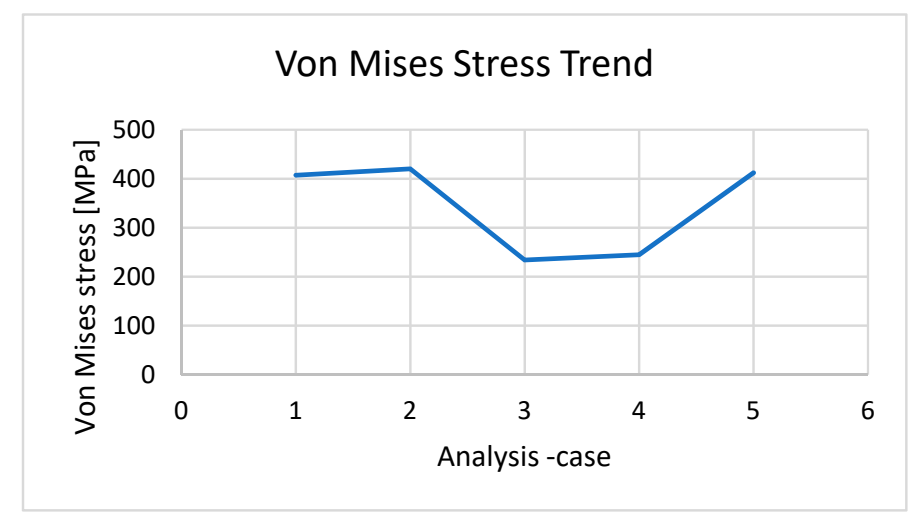

Figure 13. The von Mises stress trends between the different analyses.

In Figure 14, the diagram shows the contact pressure trends between the different analyses.

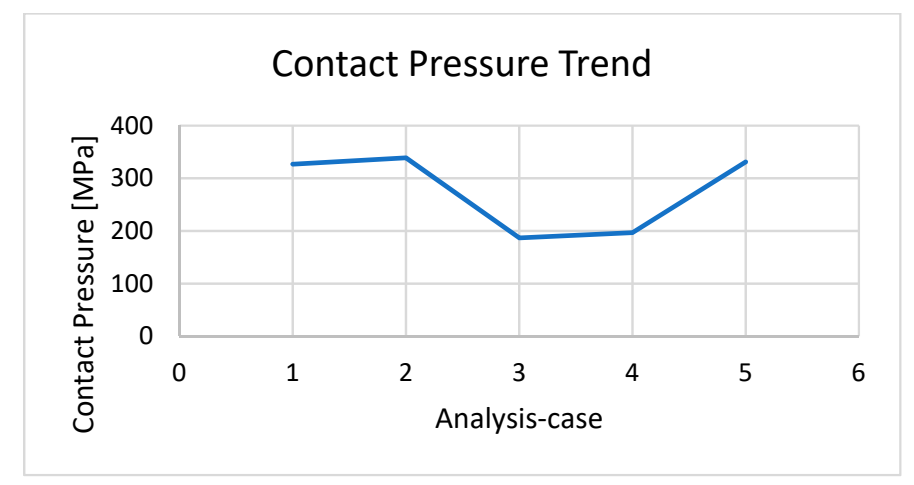

Figure 14. Contact pressure trends between the different analyses. 
Finally, we can see that the contact pressure distribution was correct, which allowed us to say that the analyses were carried out in a proper and accurate manner, providing reliable results.

\subsection{Difference Static and Dynamic Analyses}

The static analyses were mainly carried out with the aim of setting all of the basic parameters necessary for the simulations (the type of material, friction, constraint conditions, and contact algorithms used). Once all of the basic parameters had been appropriately set (by checking for the presence of any penetration and assessing that the distribution and stress values were acceptable), the model was further complicated by inserting an airbox and carrying out coupled Eulerian-Lagrangian (CEL) analyses [40-42]. The parameters that affected this second type of analysis were related to the evaluation of the acoustic emissions, for which we focused on the friction, lubrication, and rotation speed. The second type of material was not included among the variables, as the required number of simulations involving analyses requiring long computation times would have greatly increased $[43,44]$.

\subsection{Coupled Eulerian-Lagrangian (CEL) Analysis of a Spur Gear Pair}

CEL analyses are very demanding in terms of the computation time; therefore, the box sizes were as small as possible in order to contain the gear wheels and limit the number of elements.

Constraint conditions were applied to avoid any disturbing effects; for example, waves could be reflected on the edges of the box walls. Indeed, the air domain was assumed to be practically infinite. The keyword used in the Abaqus input file that allowed this condition to be achieved was:

\section{“EULERIAN BOUNDARY, OUTFLOW = NON REFLECTING".}

Within the air domain, a node was chosen near the walls in order to measure the sound pressure level. Its exact position was $80 \mathrm{~mm}$ below the midpoint of the wheelbase of the two wheels. Both the distance of $80 \mathrm{~mm}$ as that of a meter has no particular meaning because they are used only as reference points to study the sound variations [45-47]. These values were only set as references to allow a comparison between the various analyses under equivalent conditions. The pressure values obtained from these analyses were then extrapolated to a distance of $1 \mathrm{~m}$ (with the following formula) with respect to the reference point (Figure 1).

$$
S P L=S P L_{r e f}-20 \log _{10}\left(\frac{r}{r_{r e f}}\right)
$$

where SPL is the sound pressure level at a distance of $1 \mathrm{~m} ; S P L_{r e f}$ is the sound pressure level at a distance of about $80 \mathrm{~mm} ; r$ is a distance of $1 \mathrm{~m}$; $r_{r e f}$ is a distance of about $80 \mathrm{~mm}$.

In this way, in order to evaluate the noise level deriving from the meshing spur gear pair, the pair was modeled with a Lagrangian formulation. The gears were in contact during their operation and were considered to be "immersed" in an air box (modeled in an Eulerian way) in order to allow the propagation of mechanical and acoustic waves inside the considered mean.

The airbox dimensions were as follows: $X=350 \mathrm{~mm} ; Y=200 \mathrm{~mm} ; Z=100 \mathrm{~mm}$. The airbox was modeled with EC3D8R brick elements; that is, an 8-node linear Eulerian brick, reduced integration, and hourglass control (Abaqus Manual). The number of Eulerian elements used was 155,382. Therefore, in order to evaluate the sound pressure level resulting from the meshing spur gear pair, different coupled Eulerian-Lagrangian analyses were carried out, putting the gears in an Eulerian mesh, which represented air (modeled as a perfect gas), since noise is characterized by pressure waves that propagate through a medium. A noise, vibration, and harshness (NVH) analysis could not be properly performed, since it could only be used to evaluate the noise resulting from rolling bearings and supporting system vibrations [48-51]. The following table (Table 3) shows the parameters that characterized the different examined conditions. 
Table 3. Parameters of the analysis.

\begin{tabular}{|c|c|c|c|c|}
\hline \multirow{2}{*}{ Condition } & \multicolumn{4}{|c|}{ Parameters } \\
\hline & Friction & Material & Lubricated Friction & Rotational Speed (RPM) \\
\hline 1 & $\mathrm{NO}$ & Steel & $\mathrm{NO}$ & 500 \\
\hline 2 & $\begin{aligned} \mu_{s} & =0.74 \\
\mu_{k} & =0.57 \\
d_{c} & =0.2\end{aligned}$ & Steel & $\mathrm{NO}$ & 500 \\
\hline 3 & $\begin{aligned} \mu_{s} & =0.74 \\
\mu_{k} & =0.57 \\
d_{c} & =0.2\end{aligned}$ & Steel & NO & 1500 \\
\hline 4 & $\begin{aligned} \mu_{s} & =0.74 \\
\mu_{k} & =0.57 \\
d_{c} & =0.2\end{aligned}$ & Steel & $\mathrm{NO}$ & 3000 \\
\hline 5 & $\mathrm{NO}$ & Steel & $\begin{aligned} \mu_{s} & =0.11 \\
\mu_{k} & =0.05 \\
d_{c} & =0.2\end{aligned}$ & 500 \\
\hline
\end{tabular}

As explained in [1], air was modeled as an ideal gas and entropy variation was imposed as zero $(d s=0)$. Despite friction being taken in account, no energy degradation was considered, meaning the temperature remained constant and equal to room temperature.

Regarding the friction model, the same exponential decay friction model was used. It was necessary to insert the static friction coefficient $\mu_{s}$, the kinetic friction coefficient $\mu_{k}$, and the decay coefficient $d_{c}$ as well. This model was based on Equation (1), in which $\Upsilon$ is the slip rate (Figure 15).

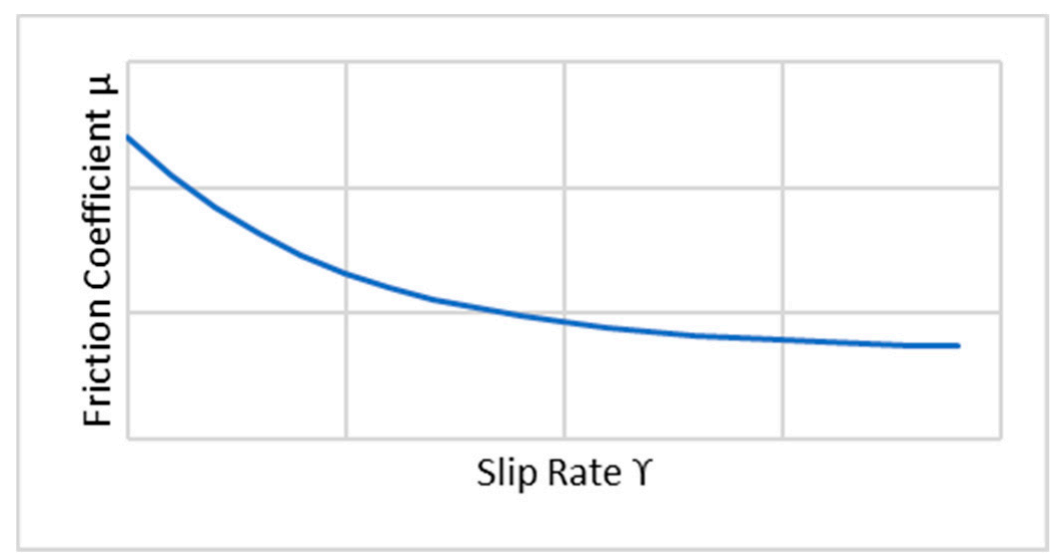

Figure 15. Exponential decay friction model.

Finally, the sound pressure level resulting from gear meshing was evaluated at a distance of $1 \mathrm{~m}$ thanks to Equation (2).

\section{Discussion}

Condition 1: The first analysis involved a steel spur gear pair and was characterized by frictionless contact and a rotational speed of 500 RPM. Figure 16 shows the sound pressure level of the meshing gears at a distance of $1 \mathrm{~m}$. 


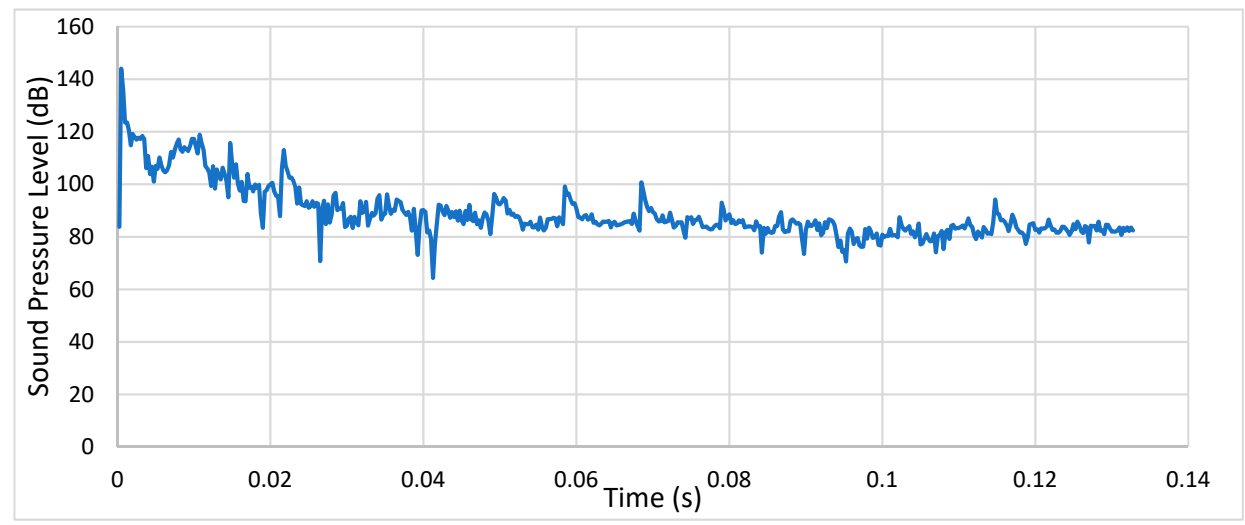

Figure 16. Condition 1: Sound pressure level spectrum.

As we can see, after the initial transient peak, the SPL stabilized between 80 and $85 \mathrm{~dB}$.

Condition 2: The second analysis involved a steel spur gear pair and was characterized by the mentioned exponential decay friction model and a rotational speed of 500 RPM. Figure 17 shows the sound pressure level of the meshing gears at a distance of $1 \mathrm{~m}$.

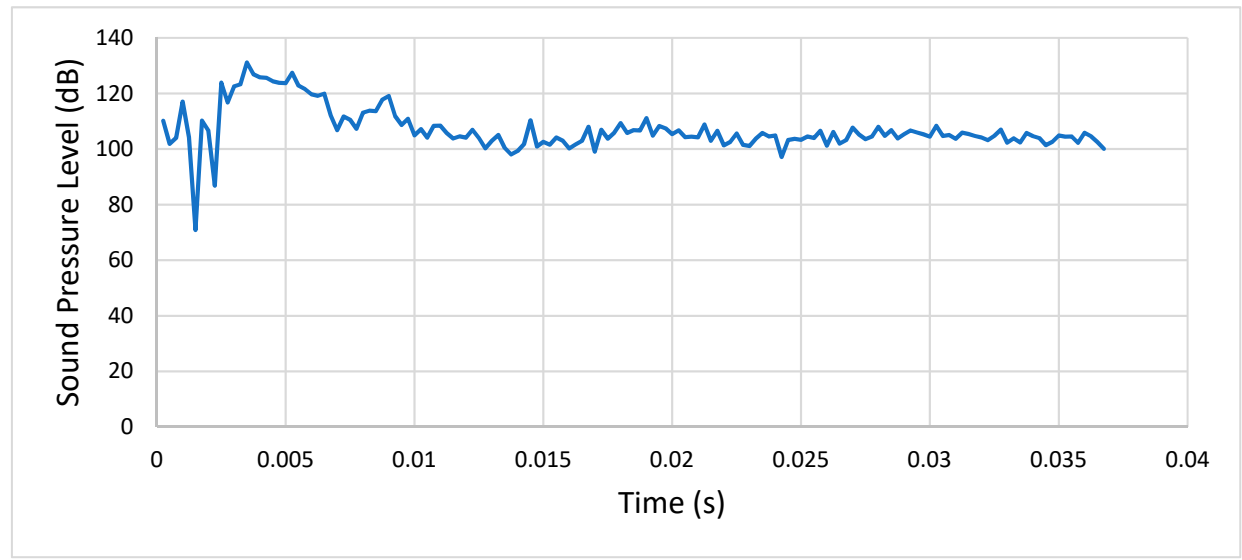

Figure 17. Condition 2: Sound pressure level spectrum.

As shown, after the initial transient peak, the SPL stabilized at over $100 \mathrm{~dB}$

Condition 3: The third analysis involved a steel spur gear pair and was characterized by the mentioned exponential decay friction model and a rotational speed of 1500 RPM. Figure 18 shows the sound pressure level of the meshing gears at a distance of $1 \mathrm{~m}$.

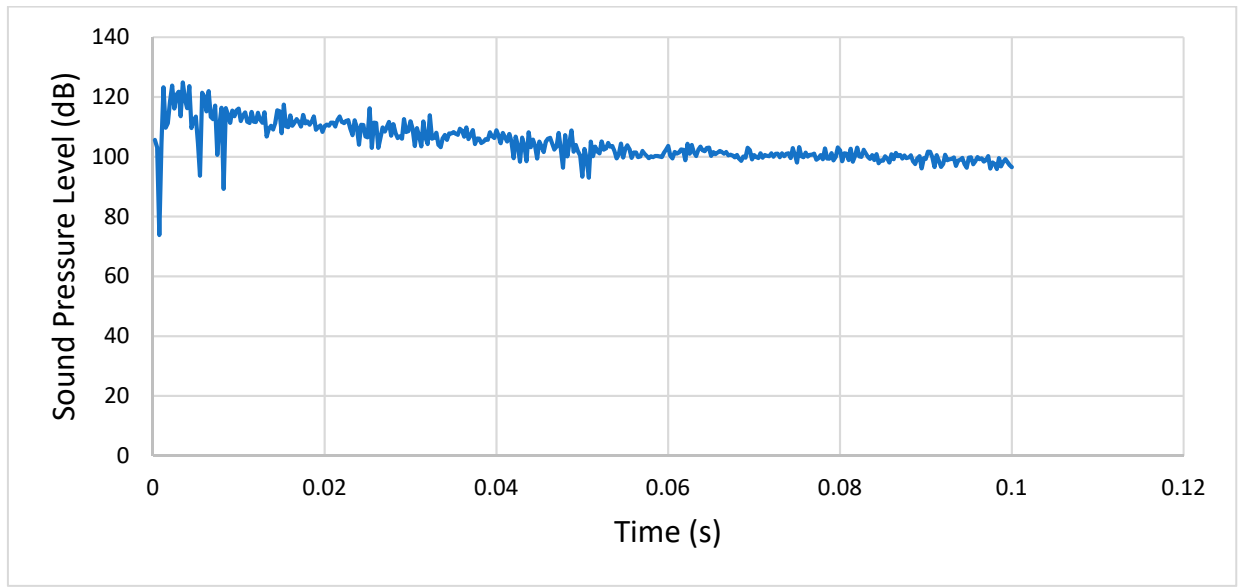

Figure 18. Condition 3: Sound pressure level spectrum. 
As we can see, after the initial transient peak, the SPL stabilized at around $100 \mathrm{~dB}$

Condition 4: The fourth analysis involved a steel spur gear and was characterized by the mentioned exponential decay friction model and a rotational speed of 3000 RPM. Figure 19 shows the sound pressure level of the meshing gears at a distance of $1 \mathrm{~m}$.

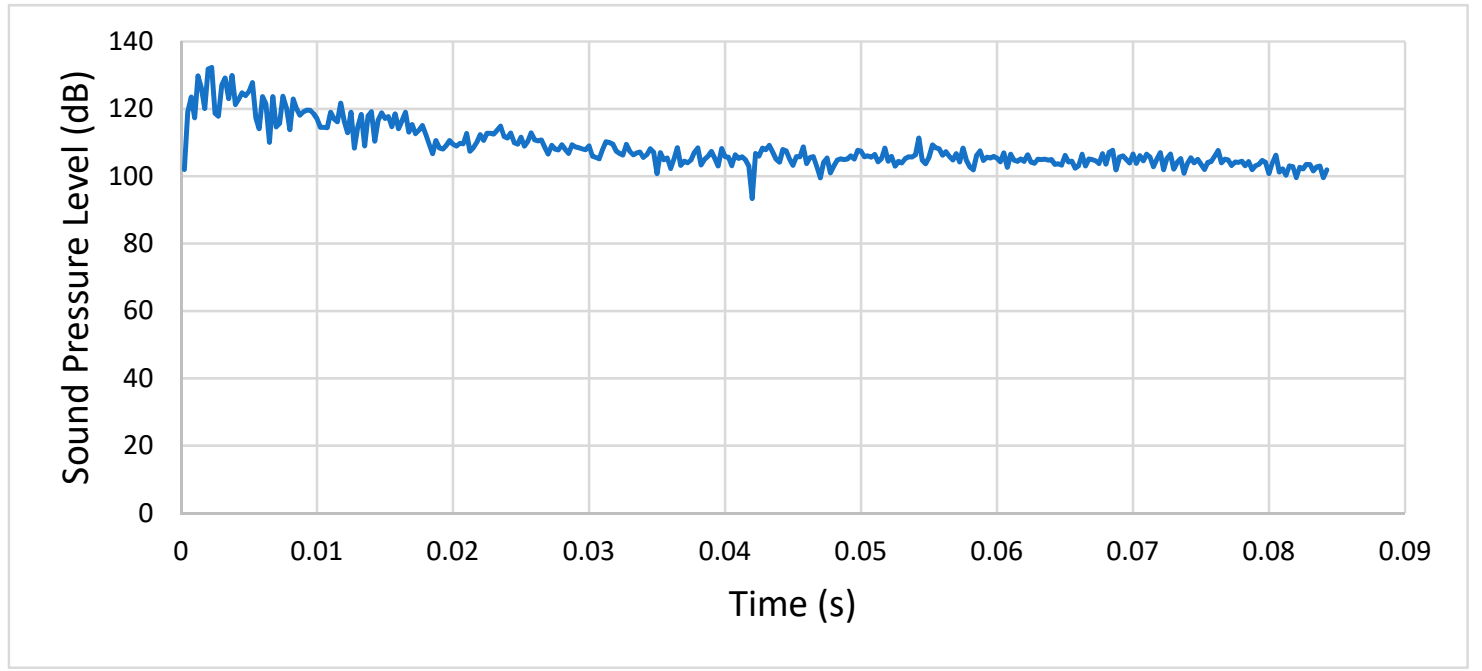

Figure 19. Condition 4: Sound pressure level spectrum.

As shown, after the initial transient peak, the SPL stabilized between 100 and $110 \mathrm{~dB}$.

Condition 5: The fifth analysis involved a steel spur gear pair and was characterized by the mentioned exponential decay friction model (lubricated friction) and a rotational speed of 500 RPM. Figure 20 shows the sound pressure level of the meshing gears at a distance of $1 \mathrm{~m}$.

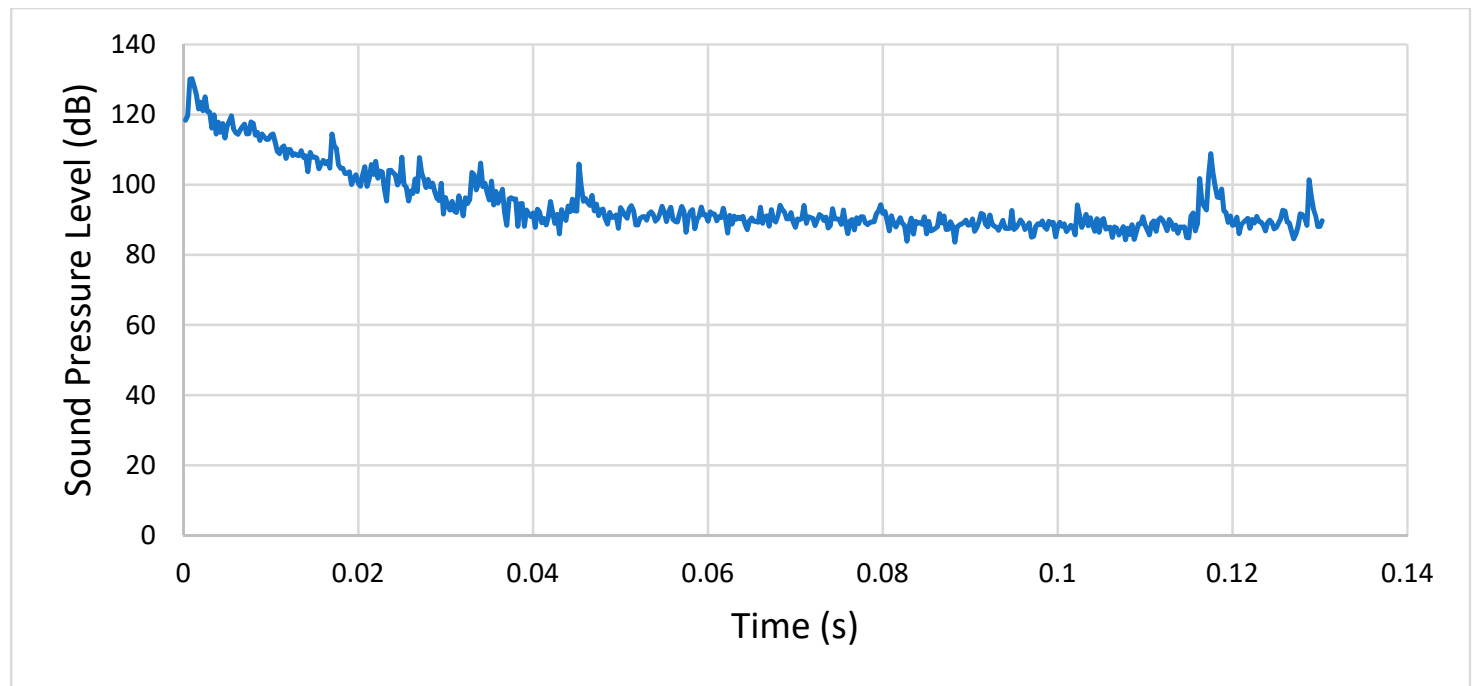

Figure 20. Condition 5: Sound pressure level spectrum.

As we can see, after the initial transient's peak, the SPL stabilized between 85 and $100 \mathrm{~dB}$.

\subsection{Comparisons}

\subsubsection{First Analysis (Condition 1) versus Second Analysis (Condition 2)}

In the first analysis, it was possible to see that the SPL stabilized between 80 and $85 \mathrm{~dB}$, while in the second one it stabilized at over $100 \mathrm{~dB}$ because of the friction's presence, which meant the gears' 
acoustic emissions were higher. Therefore, we can agree with the comments about the influence of friction on gear noise. Figure 21 shows a comparison between the respective sound pressure levels of the first and second analyses.

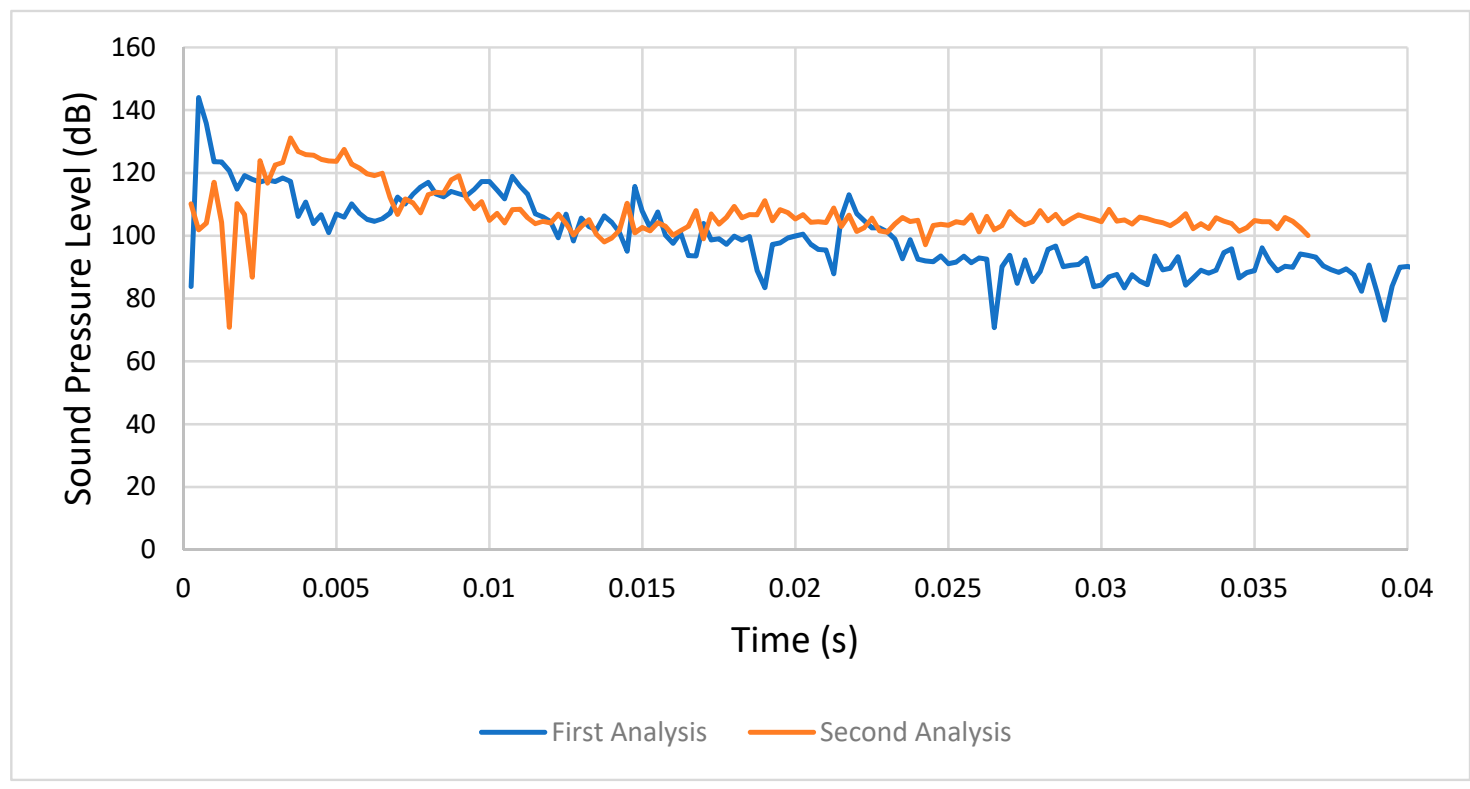

Figure 21. Comparison between the first (condition 1) and second analyses (condition 2).

\subsubsection{Third Analysis (Condition 3) versus Fourth Analysis (Condition 4)}

In the third analysis, after the initial transient peak, the SPL stabilized at around $100 \mathrm{~dB}$, while in the fourth one it stabilized between 100 and $110 \mathrm{~dB}$, because of the increased rotational speed (it went from 1500 RPM to 3000 RPM), as well as the friction. Therefore, we can agree again with the idea that the increasing rotational speed affected the acoustic emission of the meshing gears. Figure 22 shows a comparison between the respective sound pressure levels from the third and fourth analyses.

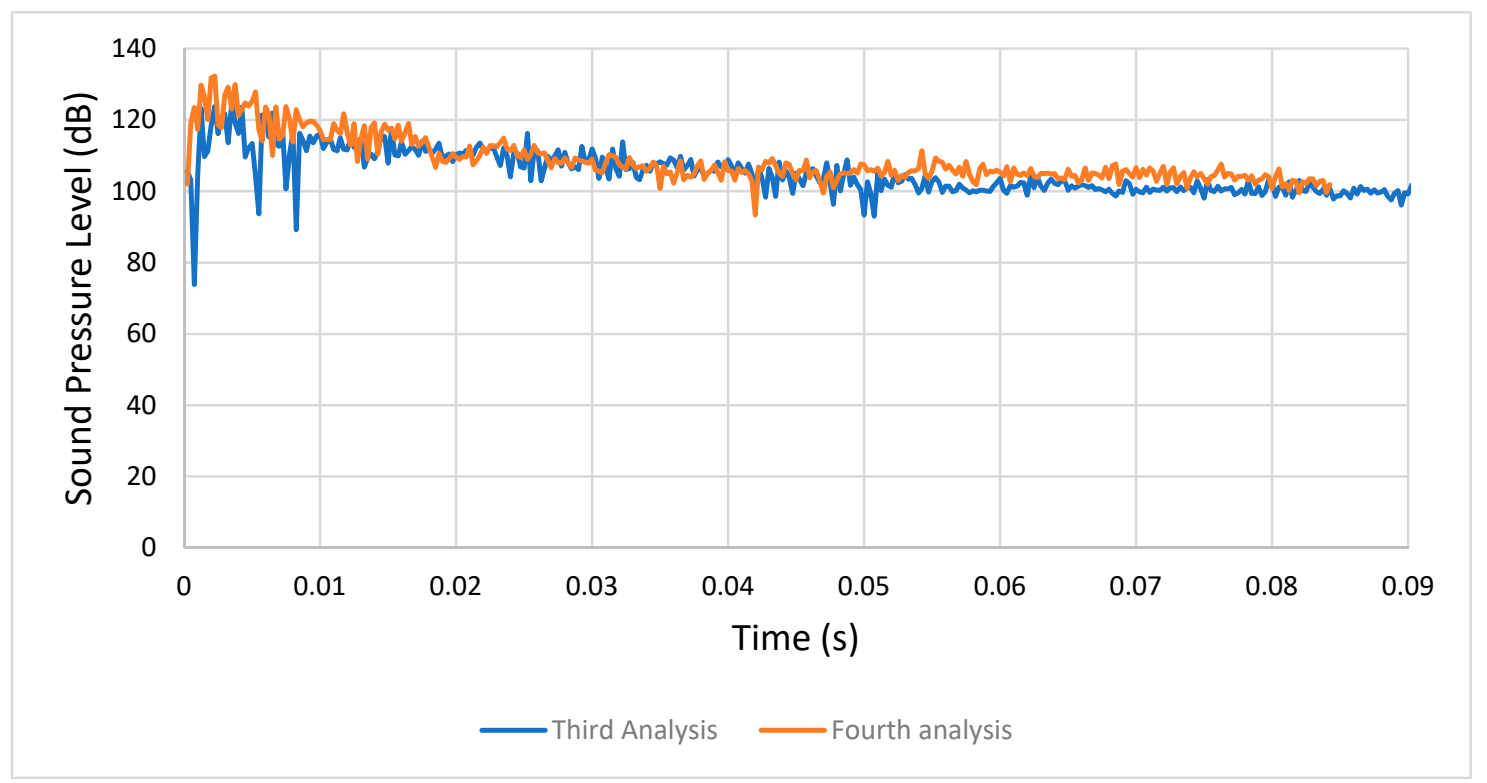

Figure 22. Comparison between the third (condition 3) and fourth analyses (condition 4). 


\subsubsection{Fourth Analysis (Condition 4) versus Fifth Analysis (Condition 5)}

In the fourth analysis the SPL stabilized between 100 and $110 \mathrm{~dB}$, while in the fifth analysis it stabilized between 80 and $100 \mathrm{~dB}$. This was due to the presence of lubricated friction and a lower rotational speed. Figure 23 shows a comparison between the respective sound pressure levels of the fourth and fifth analyses.

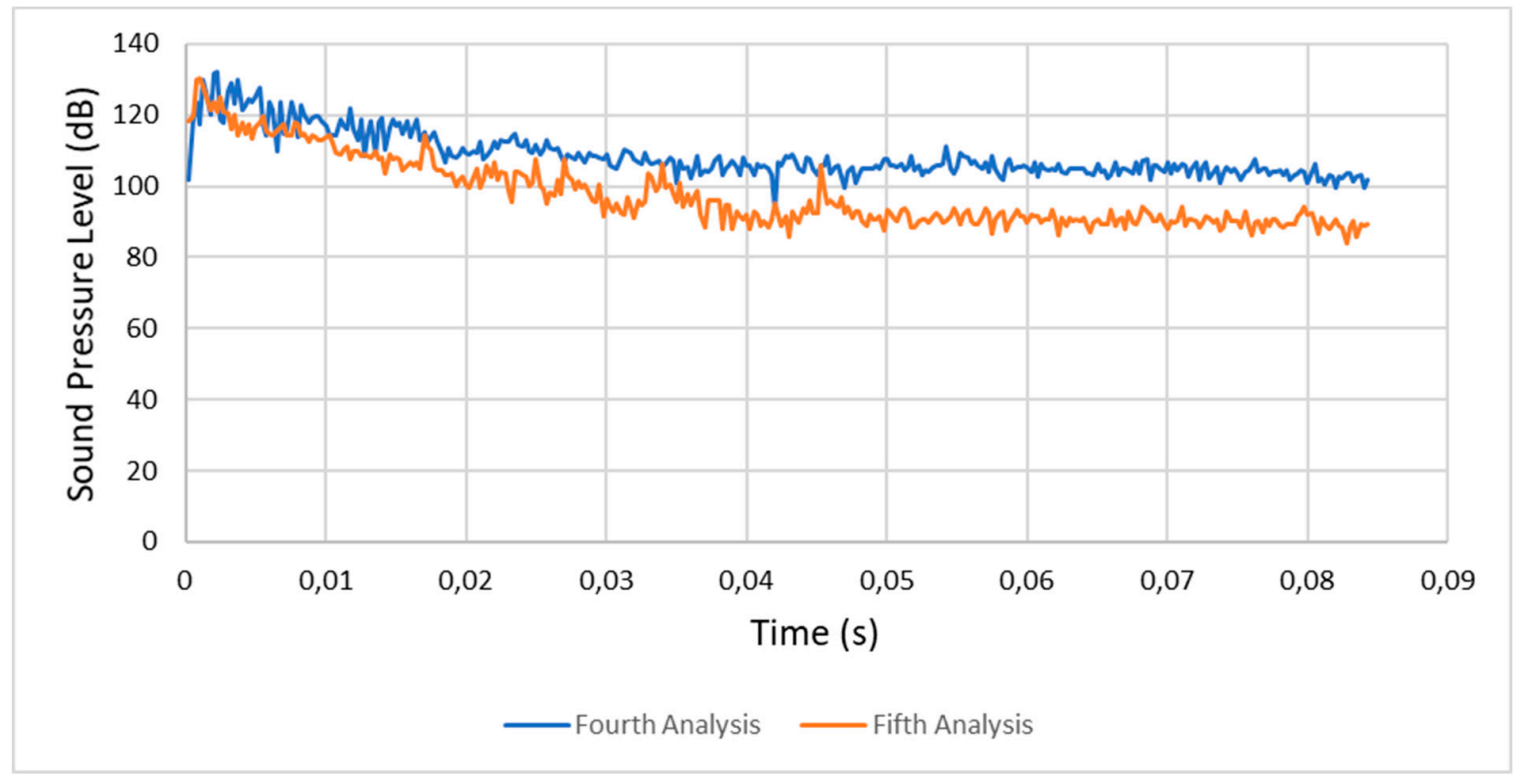

Figure 23. Comparison between the fourth (condition 4) and fifth analyses (condition 5).

\subsubsection{Second Analysis (Condition 2) versus Fifth Analysis (Condition 5)}

In the second analysis the SPL stabilized at over $100 \mathrm{~dB}$, while in the fifth analysis it stabilized between 85 and $100 \mathrm{~dB}$. This was explained by the presence of lubricated friction in the fifth analysis, meaning we found a lower level of acoustic excitation. Figure 24 shows a comparison between the respective sound pressure levels of the second and fifth analyses.

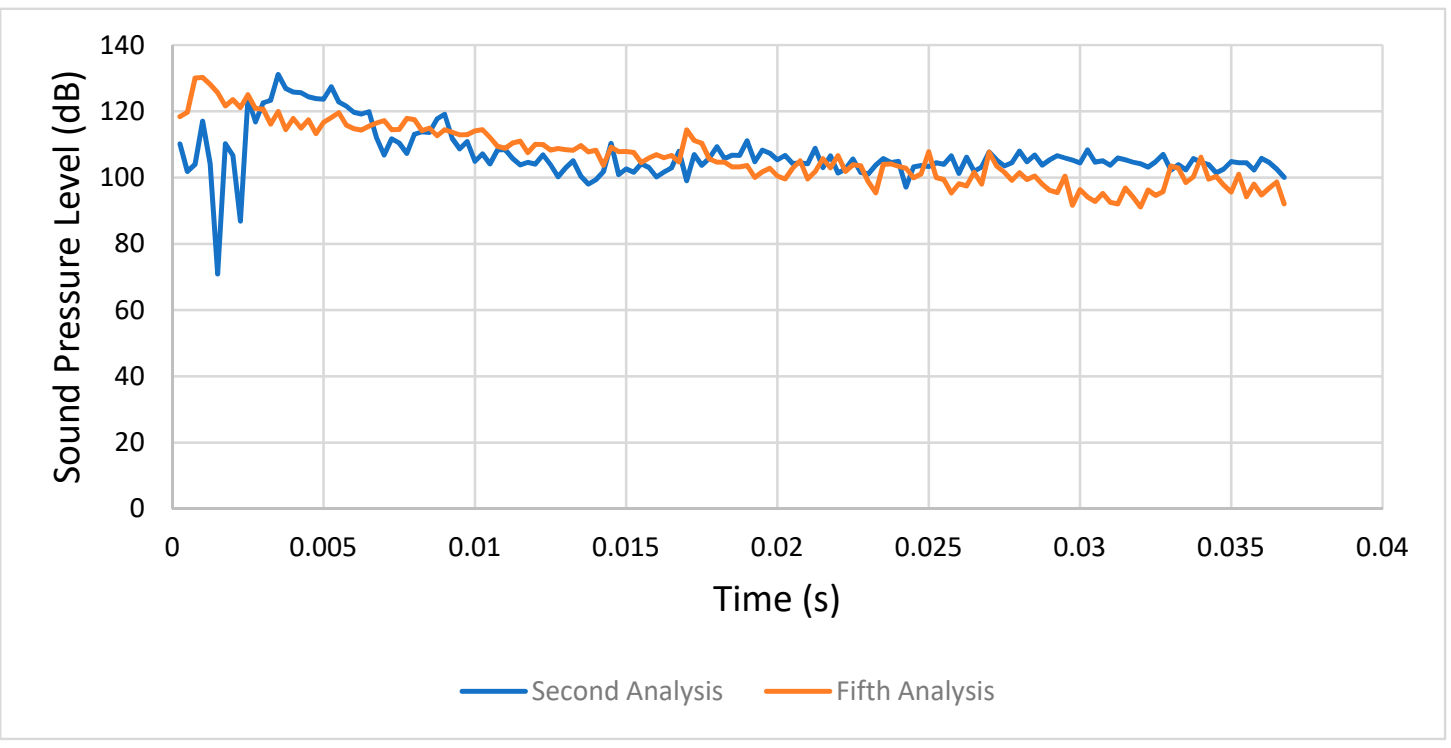

Figure 24. Comparison between the second (condition 2) and fifth analyses (condition 5). 


\subsubsection{Final Remarks}

In the model adopted for the CEL analysis, air was considered a perfect gas, but it could be changed by taking into account the viscosity of air or another state equation. Therefore, different results could have been obtained, leaving an opportunity to do more research in this field.

\section{Conclusions}

Noise reduction, at least in Europe, has become a major concern for communities [52,53]. This concern has led to great societal pressure on policy-makers, thus giving rise to stacked legislations and regulations at various levels. In Europe, two directives address noise issues, the first from a general standpoint and the second one specifically in regard to noise-related operating restrictions at the community level. Both of these EC directives refer to notions that are now commonly handled by specific industries, such as noise mapping or dose-response curves. Each of the aforementioned regulations has triggered an ongoing effort by engine manufacturers and by their associated research centers to define and follow a path toward more silent devices.

In this work, the acoustic emissions generated due to the spur gears meshing was studied and various values of the operating parameters were considered. The work was organized into two stages: (1) static analysis of the meshing gears was conducted to set and evaluate the goodness of the parameters of the model and to study the stress levels reached in the teeth; (2) coupled Eulerian-Lagrangian (CEL) analysis was performed to evaluate the noise generation. In this stage, the spur gears were "immersed" in an air box at room temperature. In this way, the pressure waves generated due to the interactions of the gears could propagate up to a reference point, where the sound pressure level was measured. Many work conditions were taken into account in the second stage in order to study how they can affect noise generation. The air was modeled as an ideal gas at room temperature and no heat flux was generated due to the friction among the gears. The entropy was set as constant ( $\mathrm{ds}=0)$ and an adiabatic process was considered. The results were in good agreement with the literature.

Future developments in this area could include analysis of how the heat generated during the meshing affects the noise generation. In this way, a damage detection model that considers the interactions between the noise generation and the entropy formation could be developed and tested on an experimental apparatus.

Author Contributions: All the authors equally contributed to carrying out the research, whose results are reported in this work. All authors have read and agreed to the published version of the manuscript.

Funding: This research received no external funding.

Conflicts of Interest: The authors declare no conflict of interest.

\section{References}

1. Wittbrodt, M.J.; Pechersky, M.J. A Hydrodynamic Analysis of Fluid Flow Between Meshing Spur Gear Teeth. J. Mech. Trans. Autom. 1989, 111, 395-401.

2. Sosnovskiy, L.A.; Sherbakov, S.S. On the Development of Mechanothermodynamics as a New Branch of Physics. Entropy 2019, 21, 1188.

3. Basaran, C. Entropy Based Fatigue, Fracture, Failure Prediction and Structural Health Monitoring. Entropy 2020, 22, 1178.

4. Kondepudi, D. Modern Thermodynamics. From Heat Engines to Dissipative Structures; Kondepudi, D., Prigogine, I., Eds.; John Wiley \& Sons: New York, NY, USA, 1998; p. 510.

5. Mase, G. Theory and Problems of Continuum Mechanics; McGraw-Hill: New York, NY, USA, 1970; p. 221.

6. Sedov, L.I. A Course in Continuum Mechanics; Wolters-Noordho: Groningen, The Netherlands, 1971; p. 242.

7. Young, C.; Subbarayan, G. Maximum Entropy Models for Fatigue Damage in Metals with Application to Low-Cycle Fatigue of Aluminum 2024-T351. Entropy 2019, 21, 967.

8. Yun, H.; Modarres, M. Measures of Entropy to Characterize Fatigue Damage in Metallic Materials. Entropy 2019, 21, 804 . 
9. Wang, J.; Yao, Y. An Entropy-Based Failure Prediction Model for the Creep and Fatigue of Metallic Materials. Entropy 2019, 21, 1104.

10. Glowacz, A. Recognition of acoustic signals of induction motor using FFT, SMOFS-10 and LSVM, Eksploatacja i Niezawodność. Maint. Reliab. 2015, 17, 569-574.

11. Glowacz, A. Recognition of Acoustic Signals of Commutator Motors. Appl. Sci. 2018, 8, 2630.

12. Armentani, E.; Sepe, R.; Parente, A.; Pirelli, M. Vibro-Acoustic Numerical Analysis for the Chain Cover of a Car Engine. Appl. Sci. 2017, 7, 610.

13. Armentani, E.; Caputo, F.; Esposito, L.; Giannella, V.; Citarella, R. Multibody Simulation for the Vibration Analysis of a Turbocharged Diesel Engine. Appl. Sci. 2018, 8, 1192.

14. Armentani, E.; Trapani, R.; Citarella, R.; Parente, A.; Pirelli, M. FEM-BEM Numerical Procedure for Insertion Loss Assessment of an Engine Beauty Cover. Open Mech. Eng. J. 2013, 7, 27-34.

15. Ghosh, S.S.; Chakraborty, G. On optimal tooth profile modification for reduction of vibration and noise in spur gear pairs. Mech. Mach. Theory 2016, 105, 145-163.

16. Axel Baumann, A.; Bertsche, B. Experimental study on transmission rattle noise behaviour with particular regard to lubricating oil. J. Sound Vib. 2015, 341, 195-205.

17. Sharma, A.; Aggarwal, M.L.; Singh, L. Experimental investigation into the effect of noise and damping using composite spur gear. Mater. Today Proc. 2017, 4, 2777-2782.

18. Sharma, R.B.; Parey, A.; Tandon, N. Modelling of acoustic emission generated in involute spur gear pair. J. Sound Vib. 2017, 393, 353-373.

19. Kopsch, F. The cost of aircraft noise-Does it differ from road noise? A meta-analysis. J. Air Transp. Manag. 2016, 57, 138-142.

20. Ducobu, F.; Filippi, E.; Arrazola, P.J.; Rivière, E.; Ortis de Zarate, G.; Madariaga, A. The CEL method as an alternative to the current modelling approaches for Ti6Al4V orthogonal cutting simulation. Procedia Cirp 2017, 58, 245-250.

21. Chang, H.; Tang, H. Review and Comparison of Clock Jitter Noise Reduction Techniques for Lowpass Continuous-Time Delta-Sigma Modulators. J. Low Power Electron. Appl. 2017, 7, 22.

22. Xiao, D.; Ding, J.; Li, X.; Huang, L. Gear Fault Diagnosis Based on Kurtosis Criterion VMD and SOM Neural Network. Appl. Sci. 2019, 9, 5424.

23. Formato, G.; Romano, R.; Formato, A.; Sorvari, J.; Koiranen, T.; Pellegrino, A.; Villecco, F. Fluid-Structure Interaction Modeling Applied to Peristaltic Pump Flow Simulations. Machines 2019, 7, 50.

24. Feng, Z.; Zhang, D.; Zuo, M.J. Planetary Gearbox Fault diagnosis via Joint Amplitude and Frequency Demodulation Analysis Based on Variational Mode Decomposition. Appl. Sci. 2017, 7, 775.

25. Zhang, R.; Gu, X.; Gu, F.; Wang, T.; Ball, A.D. Gear Wear Process Monitoring Using a Sideband Estimator Based on Modulation Signal Bispectrum. Appl. Sci. 2017, 7, 274.

26. Neubauer, P.; Bös, J.; Melz, T. Evaluation of the gear noise reduction potential of geometrically uneven inequidistant gears. J. Sound Vib. 2020, 473, 115234.

27. Formato, A.; Guida, D.; Ianniello, D.; Villecco, F.; Lenza, T.L.; Pellegrino, A. Design of Delivery Valve for Hydraulic Pumps. Machines 2018, 6, 44.

28. Huang, P.; Xu, L.; Luo, C.; Zhang, J.; Chi, F.; Zhang, Q.; Zhou, J. A Study on Noise Reduction of Gear Pumps of Wheel Loaders Based on the ICA Model. Int. J. Environ. Res. Public Health. 2019, 16, 999.

29. Chen, Z.; Shao, Y. Mesh stiffness calculation of a spur gear pair with tooth profile modification and tooth root crack. Mech. Mach. Theory. 2013, 62, 63-74.

30. Yuksel, C.; Kahraman, A. Dynamic tooth loads of planetary gear sets having tooth profile wear. Mech. Mach. Theory 2004, 39, 695-715.

31. Liu, G.; Parker, R.G. Dynamic modeling and analysis of tooth profile modification for multimesh gear vibration. J. Mech. Design. 2008, 130, 121402.

32. Sun, X.; Liu, H.; Song, W.; Villecco, F. Modeling of Eddy Current Welding of Rail: Three-Dimensional Simulation. Entropy 2020, 22, 947.

33. Živković, M.; Dašić, P.; Predrag, P. Analysis of the Comparative Advantages of Gear Pumps Indicators. Lect. Notes Netw. Systems. 2020, 76, 158-164.

34. Zhang, Y.; Sydorenko, I.; Tonkonogyi, V.; Bovnegra, L.; Dašić, P. Structural Analysis of Direct Passive Pressure Reducing Valves Using Modified Kinematic Graphs. Lect. Notes Netw. Syst. 2020, 128, 114-121. 
35. Zhang, Z.; Wu, Y.; Zhang, R.; Jiang, P.; Liu, G.; Ahmed, S.; Dong, Z. Novel Transformer Fault Identification Optimization Method Based on Mathematical Statistics. Mathematics 2019, 7, 288.

36. Chen, Y.; Ishibashi, A. Investigation of noise and vibration of planetary gear drives. Gear Technol. 2006, 23, 48-55.

37. Inapolat, M.; Kahraman, A. A theoretical and experimental investigation of modulation sidebands of planetary gear sets. J. Sound Vib. 2009, 323, 667-696.

38. Salvati, L.; d'Amore, M.; Fiorentino, A.; Pellegrino, A.; Sena, P.; Villecco, F. Development and Testing of a Methodology for the Assessment of Acceptability of LKA Systems. Machines 2020, 8, 47.

39. Gill-Jeong, C. Numerical study on reducing the vibration of spur gear pairs with phasing. J. Sound Vib. 2010, 329, 3915-3927.

40. Pappalardo, C.M.; Guida, D. An inverse dynamics approach based on the fundamental equations of constrained motion and on the theory of optimal control. In Proceedings of the 24th Conference of the Italian Association of Theoretical and Applied Mechanics (AIMETA 2019), Rome, Italy, 15-19 September 2019; pp. 336-352.

41. Sicilia, M.; De Simone, M.C. Development of an Energy Recovery Device Based on the Dynamics of a Semi-trailer. In Proceedings of the 3rd International Conference on Design, Simulation, Manufacturing: The Innovation Exchange, (DSMIE 2020), Kharkiv, Ukraine, 9-12 June 2020; pp. 74-84.

42. Chen, X.; Hu, Q.; Zhu, C. Numerical Analysis on Load Sharing Characteristics of Multistage Face Gears in Planetary Transmission. Mech. Mach. Sci. 2020, 77, 63-83.

43. Formato, A.; Ianniello, D.; Romano, R.; Pellegrino, A.; Villecco, F. Design and Development of a New Press for Grape Marc. Machines 2019, 7, 51.

44. Wang, C.; Li, H.; Ou, J.; Hu, R.; Hu, S.; Liu, A. Identification of planetary gearbox weak compound fault based on parallel dual-parameter optimized resonance sparse decomposition and improved MOMEDA. Meas. J. Int. Meas. Confed. 2020, 165, 108079.

45. De Simone, M.C.; Guida, D. Experimental investigation on structural vibrations by a new shaking table. In Proceedings of the 24th Conference of the Italian Association of Theoretical and Applied Mechanics, (AIMETA 2019), Rome, Italy, 15-19 September 2019; pp. 819-831.

46. Cheng, L.I.; Jianzhong, L.I.; Song, M.U.; Youliang, S.U.; Tao, W.; Kai, J. Simulation analysis of the tooth modification about wind power gearbox based on Romax software. Mater. Sci. Eng. 2020, 788, 012005.

47. Gäbel, G.; Millitzer, J.; Atzrodt, H.; Herold, S.; Mohr, A. Development and Implementation of a Multi-Channel Active Control System for the Reduction of Road Induced Vehicle Interior Noise. Actuators 2018, 7, 52.

48. Naviglio, D.; Formato, A.; Scaglione, G.; Montesano, D.; Pellegrino, A.; Villecco, F.; Gallo, M. Study of the Grape Cryo-Maceration Process at Different Temperatures. Foods 2018, 7, 107.

49. Manca, A.G.; Pappalardo, C.M. Topology optimization procedure of aircraft mechanical components based on computer-aided design, multibody dynamics, and finite element analysis. In Proceedings of the 3rd International Conference on Design, Simulation, Manufacturing: The Innovation Exchange (DSMIE 2020), Kharkiv, Ukraine, 9-12 June 2020; pp. 159-168.

50. Lei, Y.; Hou, L.; Fu, Y.; Hu, J.; Chen, W. Research on vibration and noise reduction of electric bus gearbox based on multi-objective optimization. Appl. Acoust. 2020, 158, 107037.

51. Tang, Z.P.; Chen, Z.X.; Sun, J.P.; Hu, Y.T.; Zhao, M. Noise prediction of traction gear in high-speed electric multiple unit. Int. J. Simul. Model. 2019, 18, 720-731.

52. Formato, A.; Ianniello, D.; Pellegrino, A.; Villecco, F. Vibration-Based Experimental Identification of the Elastic Moduli Using Plate Specimens of the Olive Tree. Machines 2019, 7, 46.

53. Kazaz, L.; Pfister, C.; Ziegler, P.; Eberhard, P. Transient gear contact simulations using a floating frame of reference approach and higher-order ansatz functions. Acta Mech. 2020, 231, 1337-1350.

Publisher's Note: MDPI stays neutral with regard to jurisdictional claims in published maps and institutional affiliations. 